Document downloaded from:

http://hdl.handle.net/10251/169175

This paper must be cited as:

Pla Moreno, B.; De La Morena, J.; Bares-Moreno, P.; Jimenez, IA. (2020). Cycle-to-cycle combustion variability modelling in spark ignited engines for control purposes. International Journal of Engine Research. 21(8):1398-1411. https://doi.org/10.1177/1468087419885754

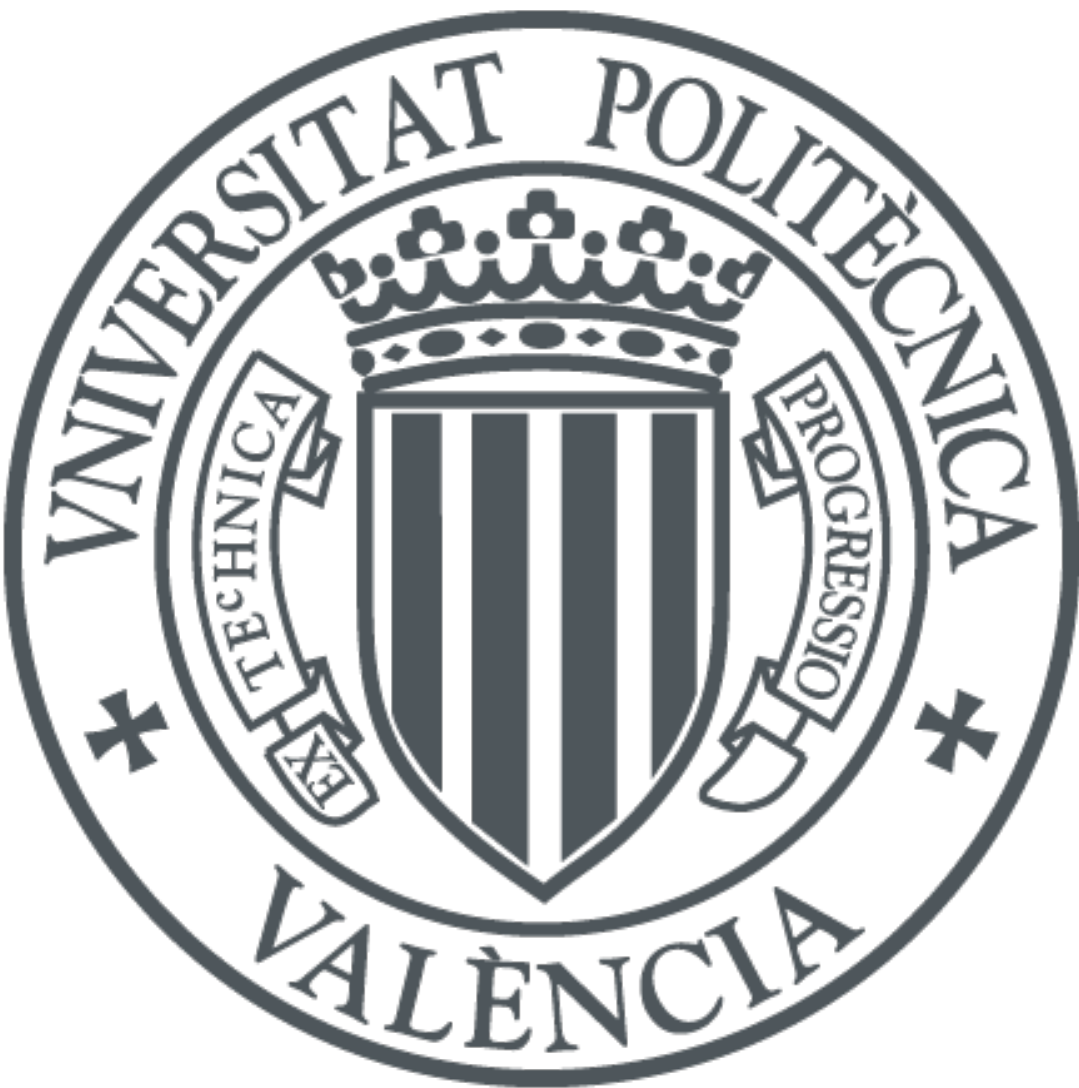

The final publication is available at

https://doi.org/10.1177/1468087419885754

Copyright SAGE Publications

Additional Information

This is the author's version of a work that was accepted for publication in International Journal of Engine Research. Changes resulting from the publishing process, such as peer review, editing, corrections, structural formatting, and other quality control mechanisms may not be reflected in this document. Changes may have been made to this work since it was submitted for publication. A definitive version was subsequently published as https://doi.org/10.1177/1468087419885754. 


\title{
Cycle-to-cycle combustion variability modelling in SI engines for control purposes
}

\section{B.Pla ${ }^{1}$ and J. De la Morena ${ }^{1}$ and P. Bares ${ }^{1} \mathrm{I}$. Jiménez ${ }^{1}$}

\begin{abstract}
A control oriented model of Spark Ignition combustion is presented. The model makes use of avaliable signals, such as Spark advance (SA), air mass, intake pressure, and lambda, to characterize, not only the average combustion evolution, but also the cycle-to-cycle variability. The conventional turbulent flame propagation model with two states, namely entrained mass and burnt mass, is improved by look-up tables at some parameters, and the cycle-to-cycle variability is estimated by propagation of an exogenous noise with a normal probabilistic distribution at the turbulent and laminar flame speed, which intends to simulate the unknowns at turbulent flow, temperature distribution, or initial kernel distribution.

The model is able to estimate which is the expected variability during the combustion evolution and might be used online for characterizing the time response of closed-loop control actions or it can be used offline to improve the control strategies without large experimental test campaigns. Experimental data from a 4 stroke commercial engine was used for calibration and validation purposes, demonstrating the capabilities of the model in steady and transient conditions.
\end{abstract}

\section{Keywords}

SI engines, Combustion model, cycle-to-cycle variability, combustion control

\section{Introduction}

New stringent legislations are including restrictions in the vehicular $\mathrm{CO}_{2}$ emissions to reduce the effect of transport sector in the global warming. Henceforth, although spark ignited (SI) engines are characterized by lower $\mathrm{NO}_{x}$ emissions in comparison with compression ignited (CI) engines, special efforts are being taken to improve SI combustion efficiency by newer controller designs.

Nowadays, the spark advance (SA) is controlled by electronic control units (ECUs) with open-loop maps stored in the memory. These maps cannot always ensure optimal combustion control because the relationship between the SA and the combustion phase its affected by many factors, such as the ambient pressure and temperature, air humidity, engine aging and wear, fuel quality, etc. Spark ignited combustion is characterized by a flame front evolution, which can be modelled by a zero dimensional model with two states, namely the entrained mass and the burnt mass ${ }^{1}$. Such model can be used offline for simulation purposes or online to predict the optimal actuation ${ }^{2}$. However, turbulence during the combustion process is complicate to predict $^{3,4}$, and disturbances at the inputs or unpredicted phenomenon might change the start of combustion and the flame propagation evolution. Some works propose using incylinder pressure for updating the parameters and consider non-calibrated phenomena that might bias the model ${ }^{5}$.

Furthermore, because of the flame front propagation principle and the increase in pressure at the combustion chamber, SI engines are affected by knock, i.e. the undesired autoignition of the end $\operatorname{gas}^{6}$. Knock is an stochastic phenomena which cannot be predicted in a deterministic manner. Although some works aim to simulate the stochastic behaviour of knock by physical models ${ }^{7,8}$ or open-loop tables ${ }^{9}$, in most of the engines, knock is avoided by retarding the spark advance at each knock event with the so named conventional knock control strategy ${ }^{10}$.

An effective method to ensure an optimal control action in the system is to use combustion indicators for feeding the control system. The combustion phase is estimated from the pressure analysis in the cylinder with a heat release analysis $^{11}$. The center of the combustion must be set in such a value that maximizes the efficiency by means of the spark advance management (SA) ${ }^{12}$. The combustion efficiency is commonly evaluated by the indicated mean effective pressure (IMEP), which might be also derived from the in-cylinder pressure trace. Finally, knock can be computed through parameters such as the maximum amplitude of pressure oscillation (MAPO) ${ }^{13}$, by a predefined threshold that is admissible for the vehicle operation ${ }^{14}$.

${ }^{1}$ CMT-Motores Térmicos, Universitat Politècnica de València, Valencia, Spain

\section{Corresponding author:}

Pau Bares, CMT-Motores Térmicos, Universitat Politècnica de València, Camino de Vera Sn, E-46022 Valencia, Spain

Email: pabamo@mot.upv.es 
These indicators can be used in two ways: by developing closed-loop combustion strategies or by employing on-board learning algorithms for real-time optimal combustion control ${ }^{15-17}$ : Zhang et al. firstly proposed a scheme with two layers to update a look-up table to control the spark advance and achieve optimal efficiency, either by pre-defining an optimal CA50 ${ }^{18}$ or by using extremum seeking to detect the optimal one ${ }^{19}$. In other works, they included a third layer to control knock under a desired level, either by a knock constraint which is updated in an open-loop map ${ }^{20}$ or with a likelihood-based control ${ }^{21}$. Corti et al. also proposed the use of extremum seeking control over the spark and the Air to fuel ratio (AFR) to optimize a cost function composed from the combustion efficiency, the knock intensity, and the exhaust temperature ${ }^{22,23}$. Popovic et al. tested different algorithms of extremum seeking for automatically optimize the variable valve timing (VVT) for minimizing the fuel consumption $^{24}$ while Hellstrom et al. used extremum seeking for finding the optimal spark advance in a flex-fuel engine ${ }^{25}$.

Nonetheless how information is used for feedback, such indicators are affected by cycle-to-cycle variations, which induces undesired noise at the control indicators and makes combustion control challenging. Combustion variation is one of the major barriers for achieving higher thermal efficiency in Spark-Ignited (SI) engines. The cyclic and cylinderto-cylinder variation can cause drop of efficiency, engine vibration, and uncomfortable noise that must be reduced. It is important that the engine is designed to minimize the combustion variation, and for a given engine design, operating conditions with high cycle-to-cycle variability should be avoided ${ }^{26}$

Many studies have been devoted to identify the causes of SI combustion variability by analysing the combustion with detailed simulations, i.e. Direct Numerical Simulation (DNS) and Large-Eddy simulations (LES), or by using specific experimental test benches, such as transparent combustion chamber optical engines. These works proved that the sources of combustion variability are diverse and complex, e.g. residual gases distribution ${ }^{27}$, velocity field around spark $^{28}$, internal kernel size ${ }^{29}$, turbulence ${ }^{30,31}$, etc. Because of the different phenomena that triggers the combustion variability, at each operating condition the laminar flame speed and the turbulent characteristics of the flame might have a different probabilistic distribution ${ }^{32}$.

Several works proposed algorithms to update lookup-tables, by designing proper filters that rejects the cycle-to-cycle variability ${ }^{33-35}$. Precise information about the variability is crucial, as there is a trade-off when updating the combustion models between robustness and time response. Gao et al. proposed an stochastic controller which uses hypothesis tests to determine if the probability distribution of the combustion indicator is in a desired range or if some correction at the spark must be applied ${ }^{36,37}$. Lee et al. used a combustion model with variability to reduce the experimental effort and calibrate an extremum seeking control approach with the spark advance and VVT as actuation ${ }^{38}$. All these studies highlight the need of cycleto-cycle variability models with low computational burden that might be used in real time for simulation purposes or for determining the parameters of the control strategy.

Most of the control-oriented models for cycle-to-cycle variation prediction are based on black-box models, such as neural networks ${ }^{39}$, and they use to be focused on the prediction of single indicators, such as IMEP or CA50. Nevertheless, the effect of the actuators and the final emissions highly depend on the shape of the heat release and detailed information about the heat release evolution variation would be beneficial for controllers based on the heat release pattern ${ }^{40}$.

The present paper aims to model the cycle-to-cycle variability of the heat release pattern by modelling the causes of the variability as a probability distribution at the laminar speed and at the turbulent speed. The model is able to predict the expected heat released evolution as well as the cycle-to-cycle variability with few available signals in commercial ECUs. The model has been tested in a four-strokes engine at various operating conditions, ranging from 1000 to $3000 \mathrm{rpm}$ and from 25 to $75 \%$ load. The paper is structured as follows: Next section presents the experimental set up. Section three introduces the flame propagation model used and the simulation of cycle-to-cycle variability developed. Section four is focused on presenting experimental results and extracting conclusions. Finally, last section highlights the main contribution of the model and proposes future work on the topic.

\section{Experimental set-up}

Several experimental tests are presented in this paper. Experimental tests have been carried out in a four stroke EURO VI SI engine boosted with turbocharger. The main characteristics of the engine are collected in the following table:

Table 1. Engine main characteristics

\begin{tabular}{ll}
\hline Combustion & SI \\
Injection & DI \\
Stroke (S) & $81.2 \mathrm{~mm}$ \\
Bore (D) & $72 \mathrm{~mm}$ \\
S/D & 1.128 \\
Number of cylinders (z) & 4 \\
Displacement & $1300 \mathrm{cc}$ \\
Compression ratio & $10.6: 1$ \\
Valves by cylinder & 4 \\
Maximum power & $120 \mathrm{~kW} @ 4500 \mathrm{rpm}$ \\
\hline
\end{tabular}

The engine is coupled in a test bench with additional measurements of temperature and pressure at the intake and exhaust manifolds. A Horiba Mexa 7100 series was used to measure the emissions of the engine. Figure 1 shows an image of the test-bench used. The overall operation of the engine has been controlled by the Electronic Control Unit, which has been bypassed with ETAS 910 for modifying the 
standard calibration. A prototyping system from National Instruments, composed from a PXIe8133 controller and acquisition modules (PXIe6356 and PXI6143), was used to acquire and process information from in-cylinder pressure and additional sensors. In-cylinder pressure was acquired every $0.5 \mathrm{CAD}$ by using spark plugs instrumented (AVL ZI33) and an optical encoder. The turbocharger is controlled by variable geometry turbine (VGT), which was controlled by the prototyping system by using a cRIO 9114 (Virtex-5 LX50 FPGA) with a NI 9759 module (H-bridge controller).

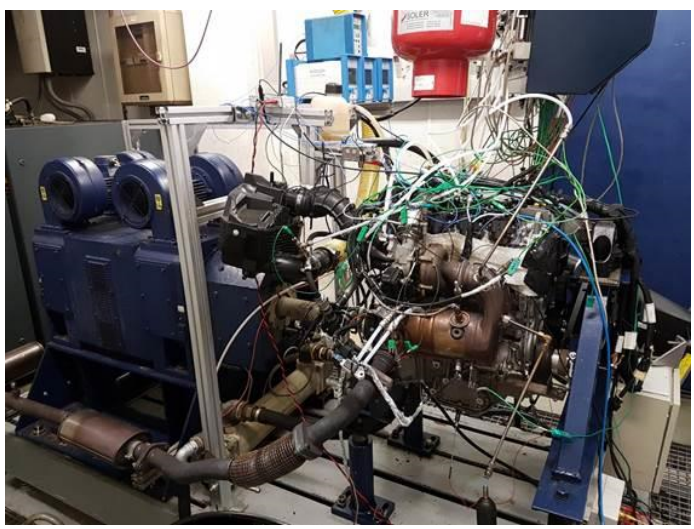

Figure 1. Test bench instrumentation

Two datasets have been used for calibration and validation purposes.

- The first set of tests has been collected to represent the engine performance over the entire operating map. It consists in 54 steady tests, where 250 in-cylinder pressure cycles have been recorded and processed. The 54 tests have been divided in 9 operating conditions characterized by intake pressure (and hence air mass flow) and engine speed. At each operating condition variations in SA have been performed until the knock limit, lambda has been maintained at 1 to ensure stoichiometric conditions. For a precise identification of knock in-cylinder pressure sensors were used: the maximum amplitude of the pressure oscillation (MAPO) was compared with a pre-defined threshold. Figure 2 shows the engine speed (top plot), intake pressure (medium plot), and spark advance (bottom plot) for each test.

- In addition of the steady test campaign, a transient test of $990 \mathrm{sec}$ has also been recorded for validation purposes. The transient test consist in step variations at various conditions (different of those used for training) in order to validate the method at diverse operating conditions and in transient operation. Figure 3 shows the evolution of the intake pressure, the engine speed, and the SA setted, during the test.

\section{Model description}

The model aims to capture the heat release fluctuations as well as the overall behaviour of the engine. In the following lines, the thermal analysis performed from the pressure signal, the model used, and the variability simulation will be described:

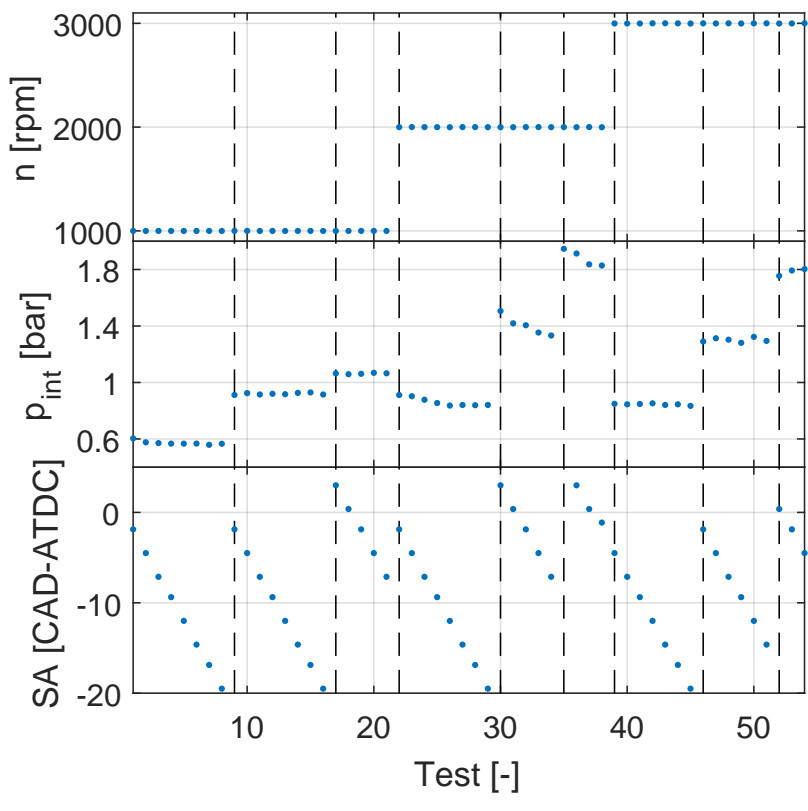

Figure 2. Operating conditions tested

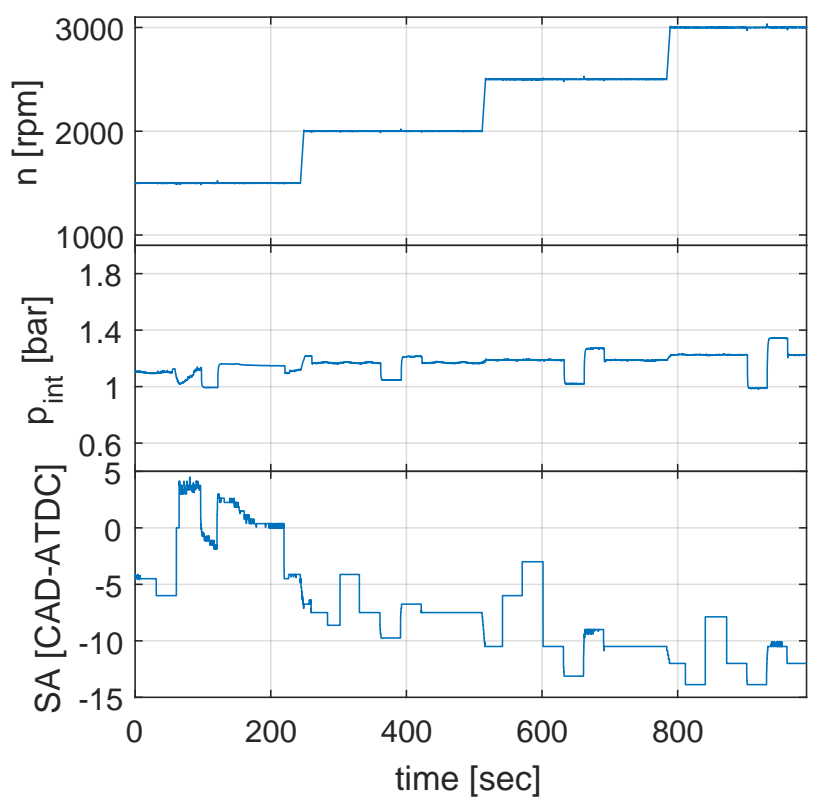

Figure 3. Tip-in and tip-out test at $1750 \mathrm{rpm}$

\section{Heat release analysis}

In-cylinder pressure is used to analyse the evolution of the heat release in experimental data, as it can be considered the most direct indicator of the combustion evolution. In-cylinder pressure sensors are used for calibration and validation purposes, however, their elevated cost confines its use in control algorithms for high cost engines.

The evolution of the heat in the control volume of the combustion chamber is commonly evaluated with the conservation of the energy and assuming ideal gas, following:

$$
Q=\frac{\gamma}{\gamma-1} p d V+\frac{1}{\gamma-1} V d p
$$


where $Q$ is the evolution of the heat in the combustion chamber, $p$ represents the in-cylinder pressure, $V$ is the instantaneous volume in the combustion chamber which can be derived from geometrical data of the engine, and $\gamma$ the specific heat capacities ratio.

The specific heat capacities ratio can be modelled by semiempirical equations. In lean mixtures, models use the air to fuel ratio, the temperature of the gases $(T)$ and the mass fraction burnt evolution to determine the properties of the gases ${ }^{41,42}$. However, in stoichiometric conditions, $\gamma$ can be modelled with much more simple functions, such as proposed by Gatowski et al. ${ }^{43}$ who suggested just a proportional dependence with the temperature. In the present work, as all the points have been collected near stoichiometric conditions, the function proposed by Egnell et al. has been used ${ }^{44}$, following:

$$
\gamma=1.38-0.2 e^{\frac{900}{T}}
$$

For obtaining the heat released from fuel, at least the wall heat transfer must be modelled through convection, such as:

$$
Q_{w}=h A_{w}\left(T-T_{w}\right)
$$

where $A_{w}$ is the area of the walls in the combustion chamber, $T_{w}$ its temperature, and $h$ the convective coefficient. The most widespread model was developed by Whoschni in $1967^{45}$, and determines the evolution of $h$ as a function of pressure, temperature, and engine speed, such as:

$$
h=C_{1} D^{-0.2} p^{0.8} T^{-0.53}\left[C_{2} \bar{c}+C_{3} K\left(p-p_{m}\right)\right]^{0.8}
$$

where $p_{m}$ is the motored pressure, $\bar{c}$ the average piston speed, $C_{1}, C_{2}$, and $C_{3}$ constants of the model, and $K$ is obtained from the volume displace, $V_{\text {dis }}$, and the conditions at the Intake Valve closing (IVC), following:

$$
K=\frac{V_{d i s} T_{I V C}}{p_{I V C} V_{I V C}}
$$

The motored pressure can be obtained by assuming a polytropic evolution, which assumes no heat released and models the evolution of $\gamma$ and the wall heat transfer in a single constant parameter, $\kappa$. In that conditions, the pressure evolution, $p_{m}$, follows:

$$
p_{m}(\alpha)=p(\operatorname{IVC})\left(\frac{V(\operatorname{IVC})}{V(\alpha)}\right)^{\kappa}
$$

Some authors use an alternative formulation, which enforces to represent the losses with a single parameter, $\kappa$, such as:

$$
\mathrm{HRR}=\frac{\kappa}{\kappa-1} p d V+\frac{1}{\kappa-1} V d p
$$

This approximation is named apparent heat release (AHR) and is used in most of control applications due to the low computational cost and for avoiding errors in complex phenomena, such as blow-by or the trapped mass estimation. A typical value used for $\kappa$ is 1.3. Such value use to compensate the effect of $\gamma$ and the wall heat transfer by slightly underestimating the heat release rate at compression and overestimate it at expansion, while maintaining a good prediction during combustion. The apparent heat release is precise for the combustion phase estimation, but exhibits significant discrepancies at the total heat release.

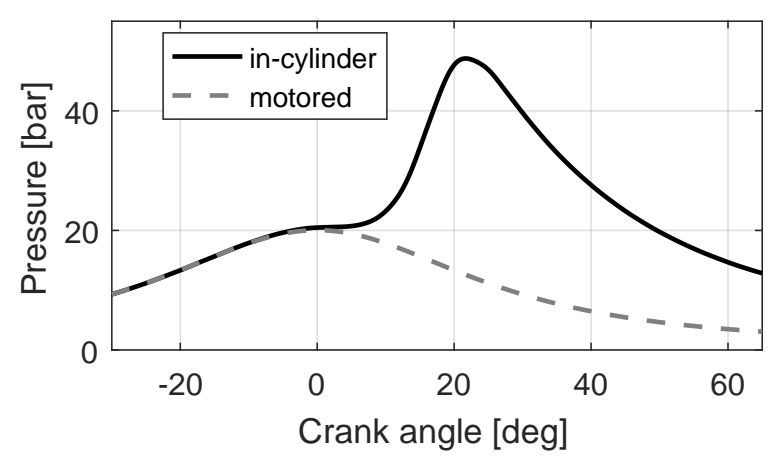

Figure 4. In-cylinder and motored pressure of a cycle at 1000 rpm and high load with the SA at -4.5 CAD-ATDC

Figure 4 shows the in-cylinder and the motored pressure from a cycle at $1000 \mathrm{rpm}$ and high load, with the SA settled at -4.5 CAD-ATDC. The $\kappa$ used here was 1.266 .

The evolution of the combustion is studied by analysing the crank angle position $(C A x)$ where a determined percentage of the energy released is achieved, which accomplishes:

$$
\int^{\alpha=C A_{x}} \operatorname{HRR} d \alpha=\frac{x \mathrm{HR}}{100}
$$

where $\mathrm{x}$ is a value comprised between 0 ant 100 . Note that $C A_{0}=$ SOC and $C A_{100}=$ EOC.

One of the major issues when analysing the combustion evolution is the determination of the end of combustion (EOC). Small divergences at the wall heat transfer prediction, or in at $\kappa$ at the AHR, are converted in virtual heat release terms at compression and expansion. These errors are rejected at compression by assuming no heat released before SA, however they are integrated at the expansion leading to late EOC positions.

One solution is the approximation of the mass fraction burnt (MFB) evolution at SI combustion by one combustion event with a vibe function shape, such as:

$$
\mathrm{MFB}=1-\exp \left(\frac{\alpha-\mathrm{SOC}}{\mathrm{EOC}-\mathrm{SOC}}\right)^{m+1}
$$

Equation 9 was used for EOC detection by using leastsquare recursive method over EOC and SOC, and assuming that combustion has a shape characterized by $m=3$.

Figure 5 shows the mass fraction evolution with the vibe curve approximation. The left axis was used to show the total heat released. The combustion efficiency is calculated as the computed energy, or heat released (HR), divided by the usable one, assuming that the gasoline energy density is $H_{c}=45 \mathrm{~kJ} / \mathrm{Kg}$, such as: 


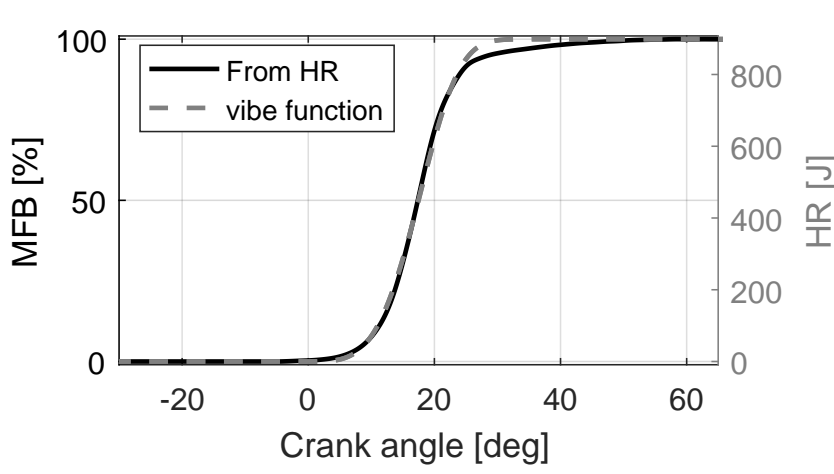

Figure 5. Mass fraction burnt of a cycle at $1000 \mathrm{rpm}$ and high load with the SA at -4.5 CAD-ATDC

$$
\eta_{c}=\frac{m_{f} H_{c}}{\mathrm{HR}}
$$

\section{Combustion model}

The model has been derived from a turbulent and laminar entrainment combustion model which was originally presented in 1974 by N. C. Blizard and J. C. Keck ${ }^{46}$. It assumes that the mass is firstly entrained at small eddies, following Equation (11) and later is burned in a characteristic time $(\tau)$. The final burnt mass is composed from the mass burnt at these eddies and the mass burnt by the flame advance, such as suggested in Equation (12).

$$
\begin{aligned}
\frac{\delta m_{e}}{\delta t} & =\rho_{u b} A_{f}\left(u_{t}+S_{l}\right) \\
\frac{\delta m_{b}}{\delta t} & =\frac{m_{e}-m_{b}}{\tau}+\rho_{u b} A_{f} S_{l}
\end{aligned}
$$

where $m_{e}$ represents the entrained mass, $m_{b}$ the mass burnt, $\rho_{u b}$ the density of unburnt gases, $A_{f}$ the flame front area, $u_{t}$ the turbulent intensity, and $S_{l}$ the laminar flame speed.

The laminar flame speed, has been derived from the semi-empirical equations suggested by $\mathrm{S}$. Poulos and $\mathrm{J}$. Heywood $^{47}$, such as:

$S_{l}=K_{1} S_{l, 0}(\lambda)\left(\frac{T_{u b}}{T_{0}}\right)^{\alpha(\lambda)}\left(\frac{p_{c y l}}{p_{0}}\right)^{\beta(\lambda)}\left(1-2.06 R G F^{0.77}\right)$

where $K_{1}$ is a calibration factor, S. Poulos and J. Heywood proposed $S_{l, 0}=0.281, \alpha=2.129$, and $\beta=-0.217$, for stoichiometric conditions $(\lambda=1)^{47}$.

The evolution of the in-cylinder pressure signal have been modelled by inverting Equation (1). Henceforth, in the discrete domain, using euler discrete differentiation, i.e. $d p_{c y l}^{k}=p_{c y l}^{k+1}-p_{c y l}^{k}$, the evolution of the in-cylinder pressure can be obtained by:

$$
p_{c y l}^{k+1}=p_{c y l}^{k}+\left(Q^{k}-p_{c y l}^{k} d V^{k} \frac{\kappa}{\kappa-1}\right) \frac{\kappa-1}{V^{k}}
$$

where the total heat evolution $(Q)$ is computed by subtracting the wall heat transfer $\left(Q_{w}\right)$ to the heat released, which is a function of the mass burnt at each step $\left(\Delta m_{b}\right)$ and a combustion efficiency $\left(\eta_{c}\right)$. Following:

$$
Q^{k}=\frac{\Delta m_{b}^{k}}{14.6} H_{c} \eta_{c}^{k}-Q_{w}^{k}
$$

The residual gas fraction $(R G F)$ was estimated from the in-cylinder pressure trace, by assuming a polytropic evolution between the exhaust valve opening and the exhaust valve closing ${ }^{48}$, such as:

$$
R G F=\left[\frac{V(E V C)}{V(E V O)}\right]\left[\frac{p(E V C)}{p(E V O)}\right]^{1 / \gamma}
$$

In the work, the RGF is an input for the model simulation but grey-box models can be used for its estimation in real time, such as suggested by Wang et al. ${ }^{49}$.

The flame has assumed to be an sphere till the combustion reaches the piston wall, when a partial semiesphere with simplifications will be assumed ${ }^{1}$. Following:

$$
A_{f}=\left\{\begin{array}{cl}
2 \pi r_{b}^{2} & \text { if } r_{b} \leq h_{c} \\
2 \pi r_{b} h_{c} & \text { otherwise }
\end{array}\right.
$$

where $h_{c}$ represents the chamber height, and the radius of the burnt gases $\left(r_{b}\right)$ is obtained from the mass burnt evolution, assuming that the burnt gases have a density approximately four times bigger than the unburned gases ${ }^{50}$, and using the following volume estimation for the aforementioned geometries:

$$
V_{f}=\left\{\begin{array}{cl}
\frac{2}{3} \pi r_{b}^{3} & \text { if } r_{b} \leq h_{c} \\
\pi r_{b}^{2} h_{c}-\frac{1}{3} \pi h_{c}^{3} & \text { otherwise }
\end{array}\right.
$$

The combustion is assumed to start at the spark ignition, and the initial radius is assumed to be constant. Note that the effect of the spark might be different depending on the position of the spark and the conditions around it. The consequences of such hypothesis have been integrated in other calibration constants.

The turbulent intensity has been estimated from the conservation of angular momentum of individual eddies, such as suggested by R.J. Tabaczynski et al. ${ }^{51}$, following:

$$
u_{t}=u_{t 0}\left(\frac{\rho_{u b}(t)}{\rho_{u b}(S A)}\right)^{\frac{1}{3}}
$$

where the increase of intensity is proportional to the cube of the proportion between the density of the unburned gases and its value at start of combustion (SOC). The initial value of turbulent intensity $\left(u_{t 0}\right)$ can be computed such as suggested by J.C. Keck ${ }^{52}$, as a function of the medium piston velocity $\left(\overline{u_{p}}\right)$ and the square root of the variation in density from the intake valve closing (IVC) to the SA:

$$
u_{t 0}=K_{2} \overline{u_{p}} \sqrt{\frac{\rho(S A)}{\rho(I V C)}}
$$

where $K_{2}$ is a calibration parameter.

R.J. Tabaczynski et al. also computed the eddy burning time $(\tau)$ as the microscale length $\left(\lambda_{m}\right)$ divided by the laminar 
flame speed, such as:

$$
\tau=\frac{\lambda_{m}}{S_{l}}
$$

The microscale length, also named Taylor microscale, might be computed by using the integral length scale $(L)$ and the Reynolds number $(\mathrm{Re})$ :

$$
\frac{\lambda_{m}}{L}=C \sqrt{R e}
$$

where the integral length scale can be computed from the distortion theory ${ }^{53}$, ending up with an expression of the micorscale length such as:

$$
\lambda_{m}=K_{3} \sqrt{\frac{\mu h_{c}(S A)}{u_{t 0}}} \rho_{u b}(S A)^{\frac{1}{3}}\left(\frac{1}{\rho_{u b}}\right)^{\frac{5}{6}}
$$

where $K_{3}$ is a constant that might be calibrated for a given engine, and $\mu$ is the dynamic viscosity, which is assumed for the unburned gases equal to that of air, following:

$$
\mu=\left(3.3 \times 10^{-7}\right) T_{u b}^{0.7}
$$

As a summary, if the combustion efficiency is calibrated, the model is able to predict the heat released as a function of the SA, the intake pressure, the injected fuel mass (and hence the air mass flow if stoichiometric conditions are assumed), the residual gasses, and the engine speed.

$$
H R=f_{c}\left(p_{\text {int }}, S A, n, R G F, m_{\text {fuel }}\right)
$$

by using three calibration constants $\left(K_{1}, K_{2}\right.$, and $\left.K_{3}\right)$, that characterize the laminar speed and turbulent intensity evolution.

Top plot in Figure 6 shows the average burning rate at $1000 \mathrm{rpm}$ and low load with a dashed line and the output of the model for three possible fittings of $K_{1}$ and $K_{2}$ with a continuous lines: The black line represents the optimal calibration, namely $K_{1}=0.49$ and $K_{2}=0.67$, the lighter grey shows the effect of increasing $K_{2}$ by $50 \%$ of the optimal value, while the darker grey line represents the best calibration when increasing $K_{2}$ a $50 \%$ over the optimal value, i.e. by compensating with a reduction of $K_{1}$. The medium plot and tops plot show the effect of such variations in the laminar flame speed and turbulent intensity evolution.

While $K_{1}$ is directly related with the laminar speed, $K_{2}$ and $K_{3}$ are related with the evolution of the turbulent intensity and its effect in the burning rate. Note that the model is able to represent the combustion with precision if the calibration parameters are properly fitted. Increasing $K_{1}$ or $K_{2}$ would accelerate the combustion rate, while the opposite effect is expected from $K_{3}$. If $K_{2}$ is increased and $K_{1}$ is decreased the shapes of the function substantially change, although the average phase evolution might be similar. The effect of $K_{3}$ is similar (but opposite) to that observed at $K_{2}$, as it is used for the computation of $\lambda_{m}$, which is also divided by $\sqrt{K_{2}}$, i.e. see Equations (20) and (23). These constants, $K_{1}, K_{2}$, and $K_{3}$, depend on the combustion chamber design, as it influences the emptying and filling procedure and the combustion evolution.

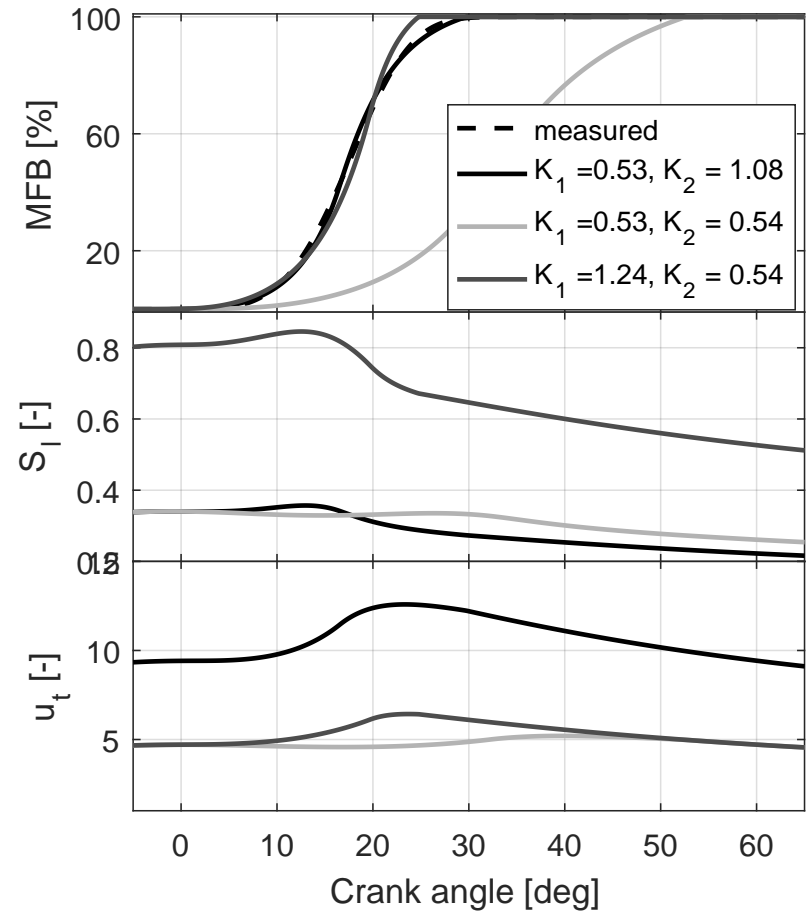

Figure 6. Mass fraction burnt, laminar speed, and turbulent intensity, obtained from the combustion model by using three combination of $K_{1}-K_{2}$.

\section{Cycle-to-cycle variability simulation}

The combustion model has been calibrated to represent the average engine operation in steady conditions. Nevertheless, the SI combustion suffers from important cycle-to-cycle variability, even when using the same actuation commands. Top plot of Figure 7 shows the combustion phase evolution of 30 cycles with grey lines and the average of all the cycles collected (200 cycles) with a black line. Bottom plot of Figure 7 shows standard deviation of the combustion phase location for these 200 cycles at each combustion location.

Most of the variability at the IMEP, and hence the combustion efficiency, is caused by the combustion phase variability as it is directly affected by the combustion location. The goal of this section is presenting a model capable of reproducing such variability by assuming that, no matter which is the disturbance triggering the variability, it can be modelled by a normal probability distribution at the laminar flame speed and at the turbulent intensity. Such as:

$$
\sigma_{C A x}(\%)=f_{\sigma}\left(N_{1}\left(\overline{K_{1}}, \mathrm{CV}_{1}\right), N_{2}\left(\overline{K_{2}}, \mathrm{CV}_{2}\right)\right)
$$

where $f_{\sigma}$ consist on the propagation of two probabilistic distributions, $N_{1}$ and $N_{2}$, on the previously presented combustion model $f_{c}$.

Each normal distribution are characterized by an average value, $\overline{K_{1}}$ and $\overline{K_{2}}$, which represent the average combustion phase evolution, and a variability, defined as the coefficient of variation $\mathrm{CV}$, such as: 


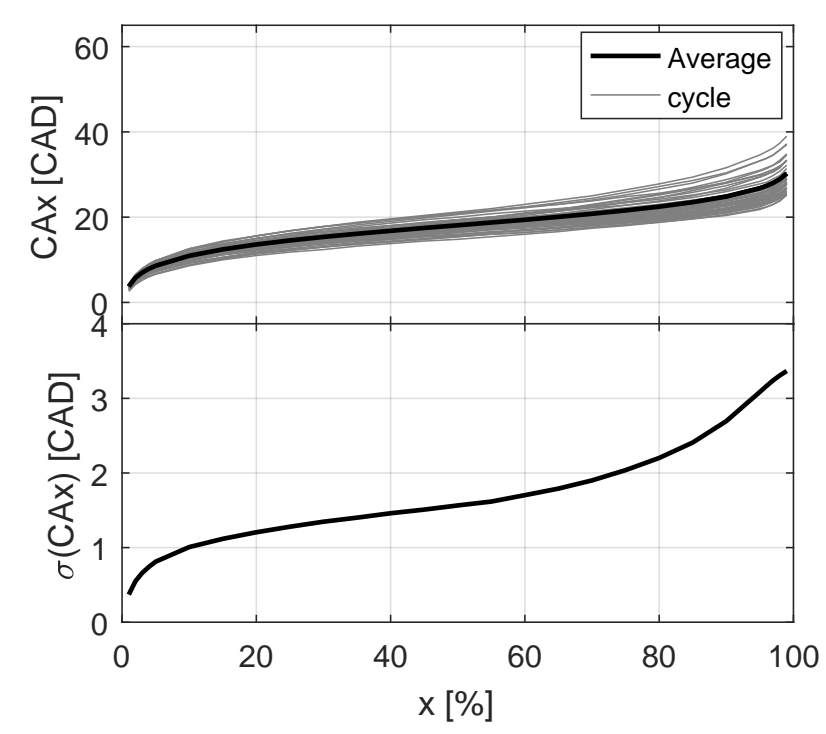

Figure 7. Average (top plot) and the standard deviation (bottom plot) of the combustion phase location at each percentage of combustion for 200 cycles at $1000 \mathrm{rpm}$ and high load with the SA at -4.5 CAD-ATDC

$$
\mathrm{CV}_{1}=\frac{\sigma\left(K_{1}\right)}{\overline{K_{1}}} 100, \mathrm{CV}_{2}=\frac{\sigma\left(K_{2}\right)}{\overline{K_{2}}} 100
$$

Figure 8 shows, with a dashed line, the experimental variability found at each percentage of the combustion phase location for the point previously presented in Figure 7, while the result of three possible combinations of $\mathrm{CV}_{1}$ and $\mathrm{CV}_{2}$ : the optimal one, only $\mathrm{CV}_{1}$, and only $\mathrm{CV}_{2}$, has been drawn with continuous lines.

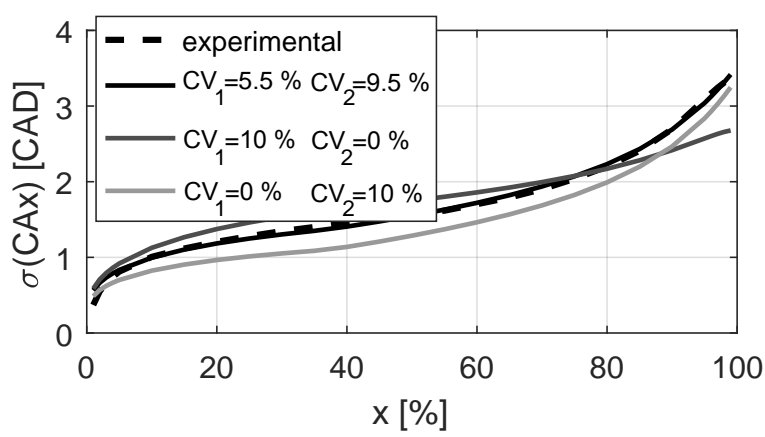

Figure 8. Comparison between the variability found with experimental data and the result of three possible combinations of $\mathrm{CV}_{1}$ and $\mathrm{CV}_{2}$

The propagation of such probability distributions should be made by discrete computation of all the possible values of $K_{1}$ and $K_{2}$ comprised in the probability spectrum, such as:

$$
\operatorname{MFB}(i, j, \alpha)=f_{c}\left(K_{1 i}, K_{2 j}\right)
$$

where $\operatorname{MFB}(\mathrm{i}, \mathrm{j}, \alpha)$ is the fuel mass burnt at cranck angle $\alpha$ when laminar flame speed and turbulent intensity are modelled by constants $K_{1 i}$ and $K_{2 j}$ respectively. Afterwards the position at each $\%$ of the combustion $\left(C A_{x i j}\right)$ is found, and finally, the average and the standard deviation of each probability function can be determined by:

$$
\begin{aligned}
\overline{C A_{x}} & =\sum_{i} \sum_{j} C A_{x i j} P_{i j} \\
\sigma\left(C A_{x}\right) & =\sqrt{\sum_{i} \sum_{j} P_{i j}\left(C A_{x i j}-\overline{C A_{x}}\right)^{2}}
\end{aligned}
$$

where $P_{i j}$ is the probability function of each combination of $K_{1 i}$ and $K_{2 j}$, which must accomplish that:

$$
\sum_{i} \sum_{j} P_{i j}=1
$$

The main problem of such model is the computational burden of recalculating the combustion phase evolution for all the possible variations. Figure 9 shows the probability function of the optimal solution, namely $\mathrm{CV}_{1}=5.5 \%$ and $\mathrm{CV}_{2}=9.5 \%$. For an adequate precision, 100 values at each dimension, ranging from 0.8 to 1.2 have been chosen. That implies running the model $100 \times 100$ times in order to obtain all the possible combustion phases.

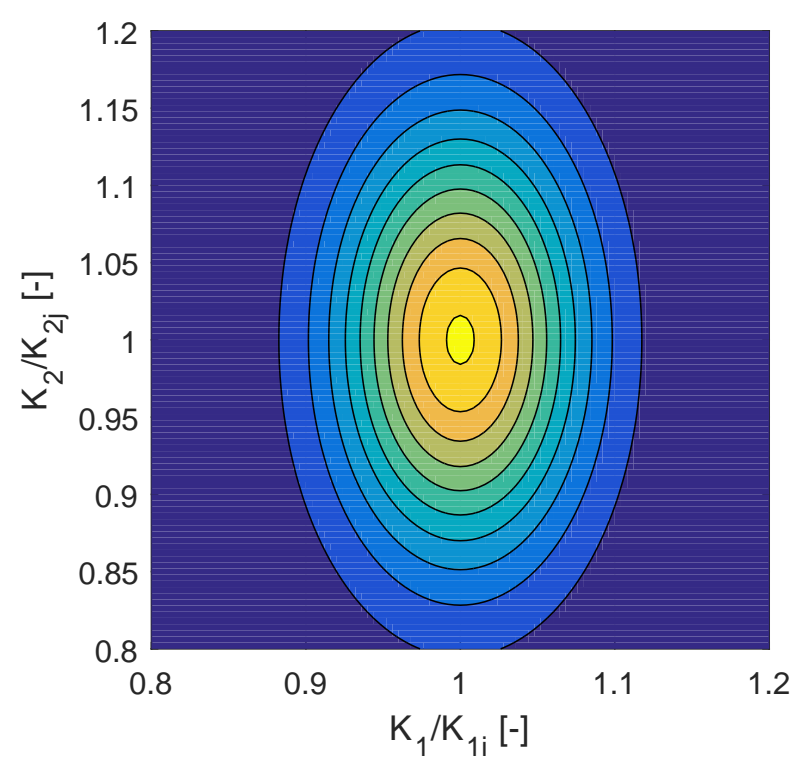

Figure 9. Probability function $P_{i j}$ of the optimal solution characterized by $\mathrm{CV}_{1}=5.5 \%$ and $\mathrm{CV}_{2}=9.5 \%$

here, the subindex $i$ and $j$ have been used for the trials at each constants, and the values at the axis have been adimensionalized to illustrate the proportional effect at each constant. From now:

$$
A_{1 i}=K_{1 i} / \overline{K_{1}}, A_{2 j}=K_{2 j} / \overline{K_{2}}
$$

With the aim of avoiding such tedious implementation, two hypothesis have been taken:

- The cross effects between $A_{1}$ and $A_{2}$ have been neglected, assuming that:

$$
C A_{x}\left(A_{1}, A_{2}\right)=\sigma\left(A_{1}, 1\right)+\sigma\left(1, A_{2}\right)
$$


- A quadratic dependence of $C A_{x}$ with each parameter, i.e. a linear function for the derivative, such as:

$$
C A_{x}=\frac{m_{i}^{2}}{2} \Delta k_{i}+d K_{i 0} \Delta k_{i}+C A_{x 0}
$$

where $C A_{x 0}$ is the average $C A_{x}$, while $m_{i}$ and $d k_{i 0}$ are constants for each parameter defining the dependence of the combustion phase evolution respect to $A_{1}$ and $A_{2}$.

With those assumptions, the variability can be simulated by running 5 times the model (three points at each dimension). Figure 10 illustrates with crosses the five iterations selected: one at the average value $\left(K_{1}\right.$ and $\left.K_{2}\right)$ and the others using a $20 \%$ variation $\left(A_{1}=[0.8,1.2]\right.$ and $\left.A_{2}=[0.8,1.2]\right)$. The derivatives have been also obtained at the circles by Euler finite differences, and finally, the evolution of the derivative has been projected from these points (pointed out by circles in Figure 10).

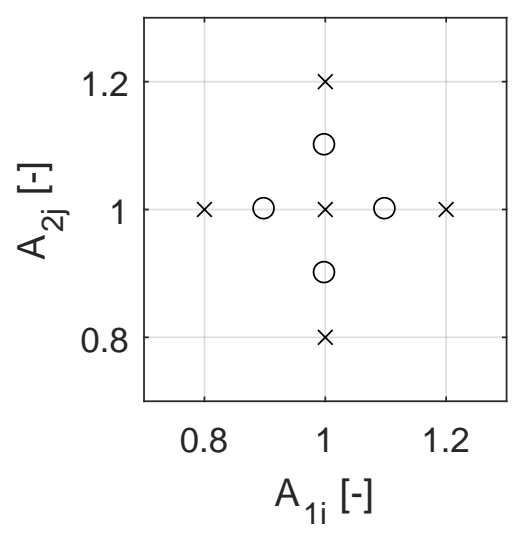

Figure 10. Simulations proposed to obtain the variability at all the range

Note that these calculations must be updated every time-step, as the model inputs, namely intake pressure, SA, injected fuel mass, residual gas fraction, and engine speed, modify the function (26).

Figure 11 shows how much is modified the location of the CA50 when varying one unit of $A_{1}$ and $A_{2}$. The experimental value obtained at 100 iterations over $A_{1}$ and $A_{2}$ is drawn with a black line, while the linear interpolation is illustrated with a grey line.

Notice that increasing $A_{1} 0.1$, i.e. increasing $K_{1}$ by a $10 \%$, the CA50 is advanced $1 \mathrm{CAD}$ but when reducing it the same quantity, combustion is retarded 1.5 CAD. The effect is lower near the SOC while it uses to increase near the EOC. Although the function is not linear, i.e. the function tends to $-\inf$ when $A_{1}$ is equal to 0 , the approximation works with sufficient accuracy for $\mathrm{CV}_{1}$ and $\mathrm{CV}_{2}$ values below $15 \%$.

Regarding the error committed due to the five-points approximation, the effect is below the $2.5 \%$ for all the combustion evolution. Figure 12 shows the discrepancies founded in percentage when computing all the possibilities with a 100x100 matrix and when using only 5 simulations.

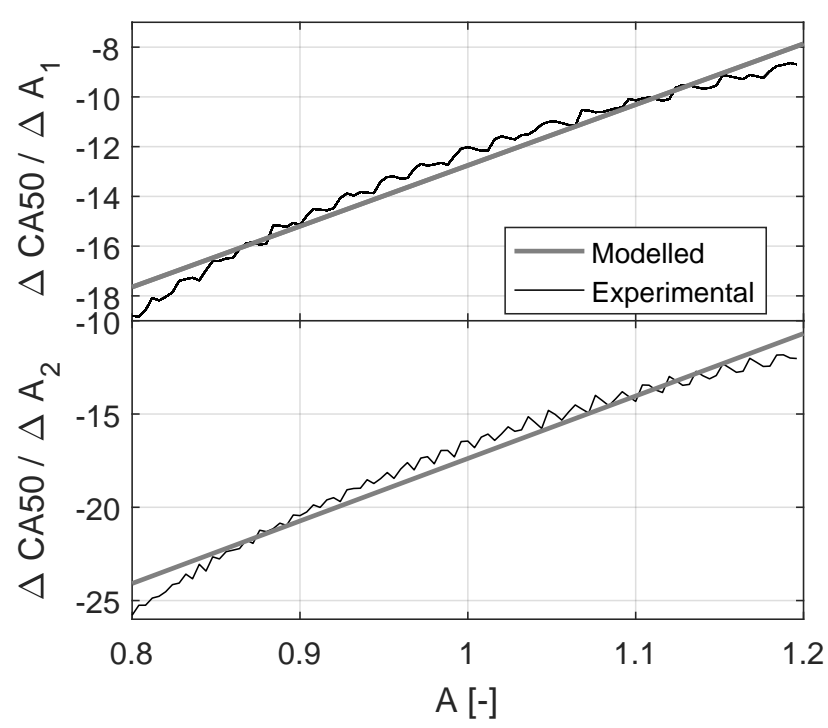

Figure 11. Variation of CA50 as a function of $k_{1}$ and $k_{2}$

The time consumed for the first procedure was $50.39 \mathrm{sec}$, while the second method proposed only took $0.0965 \mathrm{sec}$ (522 times less).

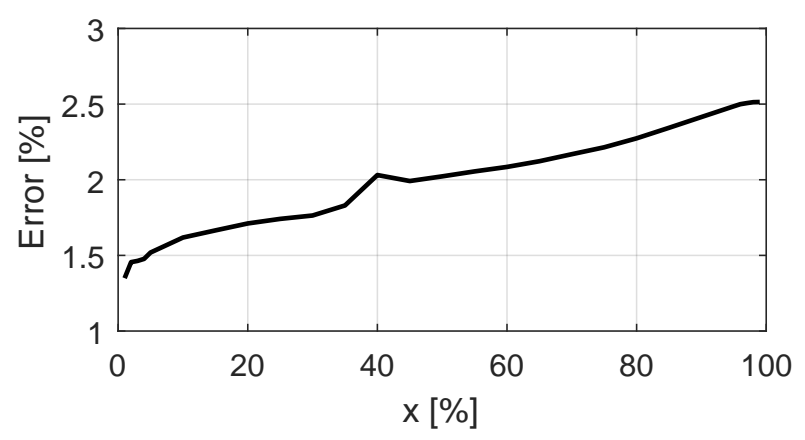

Figure 12. Discrepancies in percentage between the complete probability calculation and the five-point iterative method

\section{Results and discussion}

The model has been calibrated by using the dataset described in Figure 2. The combustion model was improved by mapping three parameters that have been tabbed as a function of the engine speed ant the intake pressure: two related with the heat release calculation, namely the combustion efficiency, and $\kappa$, and a one degree of freedom for the combustion model, $K_{2}$. The variability was simulated by propagation of two probability distributions at $K_{1}$ and $K_{2}$ characterized by two constants.

\section{Calibration of heat release analysis}

The first step is done by analysing the heat release model in order to calibrate $\kappa$, which is related with the compression procedure, and $\eta_{c}$, which is related with the combustion efficiency but also with other phenomena not contemplated in the model, such as crevice, short-circuit, blow-by, etc. 
Figures 13 and 14 shows the maps obtained for $\kappa$ and $\eta_{c}$ respectively. The 54 tests used for calibration have been marked with circles.
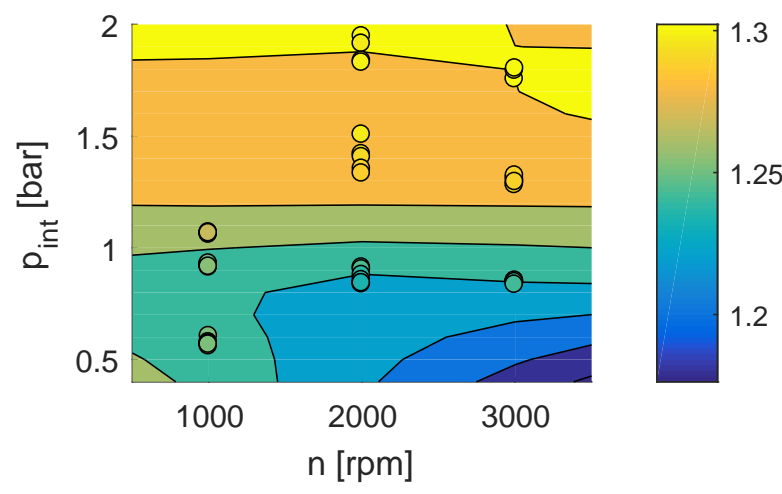

Figure 13. Open-loop map for $\kappa$

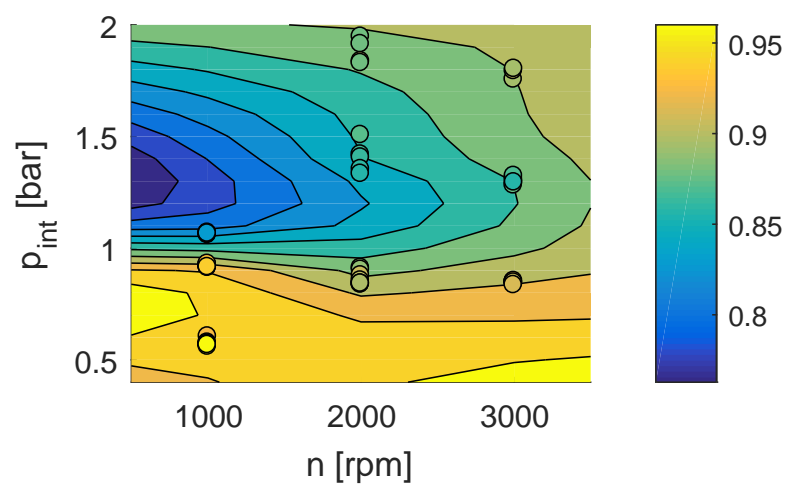

Figure 14. Open-loop map for $\eta_{c}$

Although the values of $\kappa$ and $\eta_{c}$ cannot be assumed constant and depend on the operating conditions, the influence of SA is negligible and they can be modelled with a 2D open-loop (OL) table. Figure 15 illustrates the performance of such OL maps in comparison with the data directly obtained from the in-cylinder pressure recorded.

\section{Calibration of combustion model}

Once the combustion efficiency and $\kappa$ can be obtained from the intake conditions, such as:

$$
\begin{aligned}
\kappa & =f_{\kappa}\left(p_{\text {int }}, n\right) \\
\eta_{c} & =f_{\eta}\left(p_{\text {int }}, n\right)
\end{aligned}
$$

the parameters $K_{1}, K_{2}$, and $K_{3}$ can be calibrated.

The main parameter to calibrate here is $K_{2}$, as the turbulent intensity is modelled taken as reference the moment when spark starts, and hence the discrepancies of the model depend on the operating conditions, but also with the SA.

Figure 16 shows the optimal $K_{2}$ value as a function of the SA, when fixing $K_{1}=0.65$ and $K_{3}=10$. The 9 groups of tests, at different engine speed and intake pressure, have been

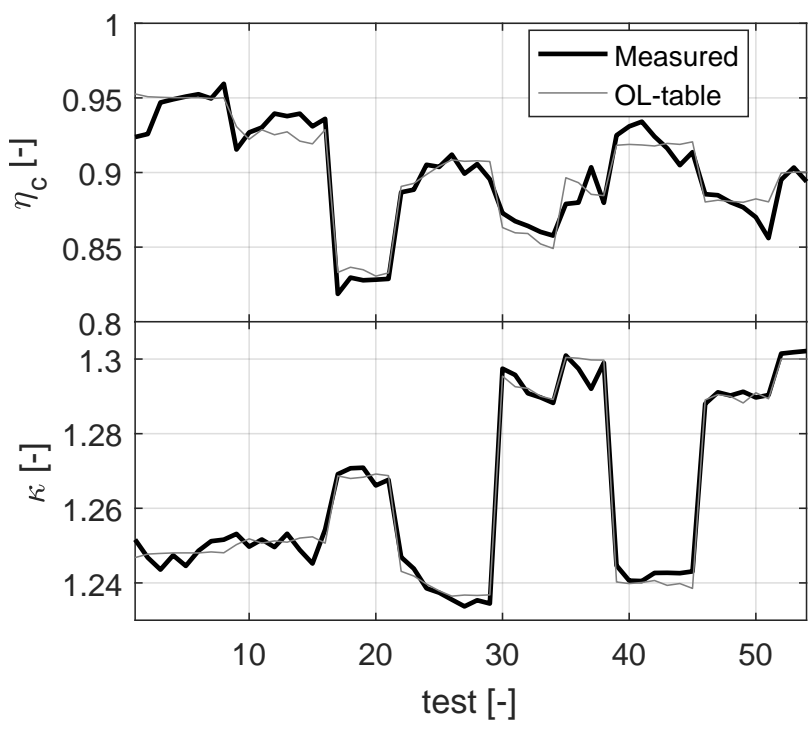

Figure 15. Measured data and extrapolated values from maps over the training dataset

coloured with different intensities of blue. No improvements were experimented when augmenting the degrees of freedom with $K_{1}$ or $K_{3}$.

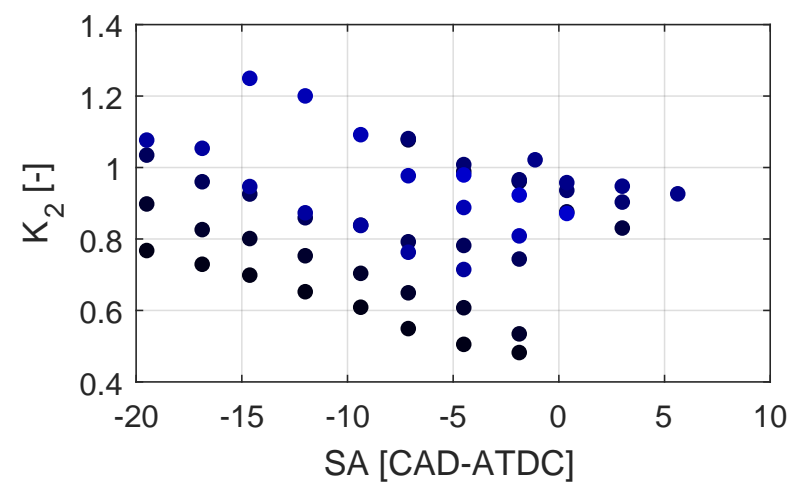

Figure 16. Values of $K_{2}$ obtained as a function of SA

As it can be seen, the dependence of $K_{2}$ with the SA seems to be linear with the SA with a constant slope of 0.02 units per CAD. Consequently, an adaptation of $K_{2}$ is proposed, following:

$$
K_{2}=K_{20}\left(n, p_{\text {int }}\right)+0.02 S A
$$

Figure 17 shows the values of the final map of $K_{20}$. This Open-loop map intends to represent the dependence of $K_{2}$ with the operating conditions while the simplification shown in Equation (37) includes the variation of $K_{2}$ with the SA. Figure 18 shows the comparison between the optimal value found at each test and the result from the model proposed.

For a control-oriented model constant values of $\mathrm{CV}_{1}=$ $5 \%$ and $\mathrm{CV}_{2}=10.25 \%$ are used. A more detailed model of $\mathrm{CV}_{1}$ and $\mathrm{CV}_{2}$ could be developed by exploring alternatives in order to characterise the variability dependence on the model inputs, e.g. by using neural networks (NN). 


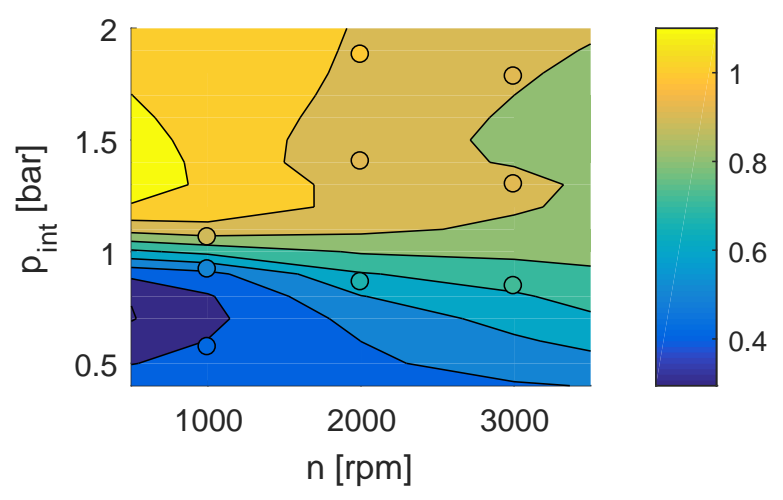

Figure 17. Open-loop map for $K_{20}$

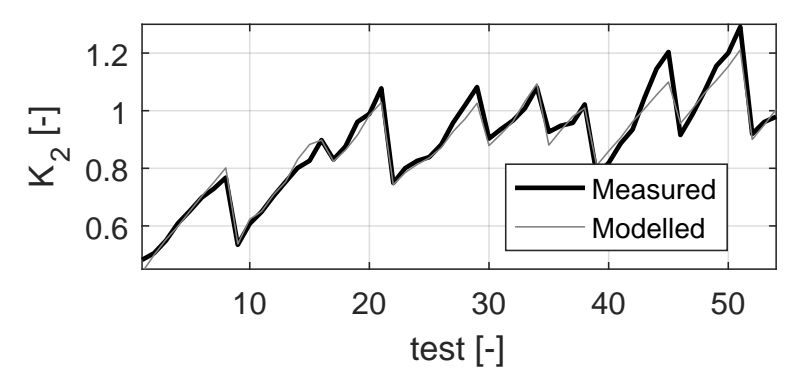

Figure 18. Comparison between the optimal values of $K_{2}$ found and the modelled ones

\section{Results on training dataset}

Figures 19 and 20 shows the result of the combustion model with a dashed line, together with the experimental data processed for the test recorded at $2000 \mathrm{rpm}$ and low load with the SA at -9 CAD-ATDC.

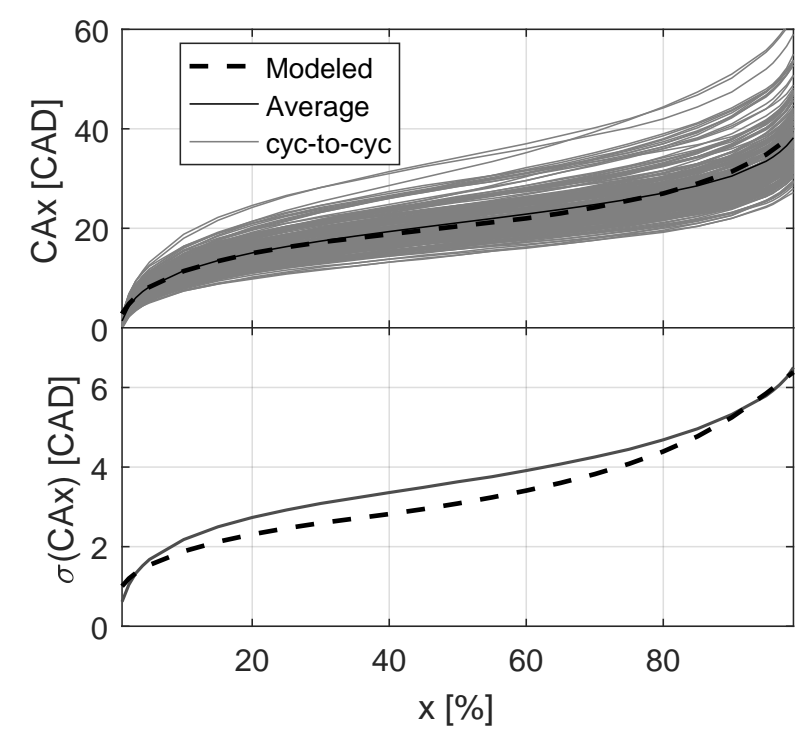

Figure 19. Result of the combustion model for each $\%$ of combustion: average (top plot) and variability (bottom plot) at $2000 \mathrm{rpm}$ and low load with the SA at -9 CAD-ATDC

It must be noticed that the model is able to precisely predict the average mass fraction burnt and the pressure evolution while achieves a good precision on the prediction

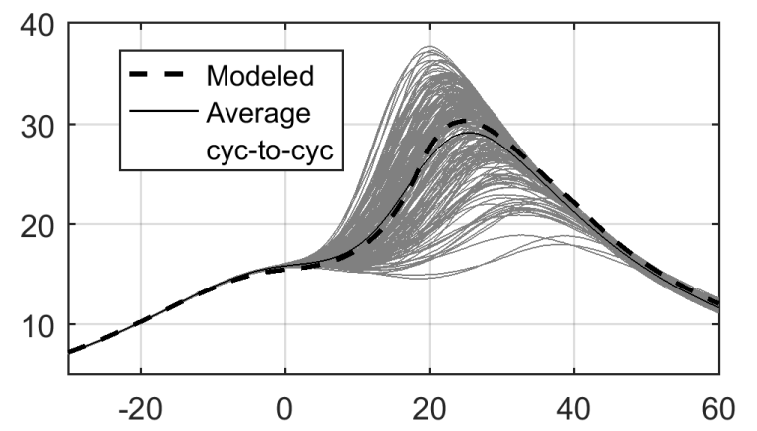

Figure 20. Result of the predicted pressure evolution at 2000 rpm and low load with the SA at -9 CAD-ATDC

of the variability. Top plot of Figure 21 shows the mean absolute error (MAE), while the bottom plot shows the mean relative error (MRE) of the 54 training test used. The error at the variability propagation has been computed at each $\%$ of the evolution.

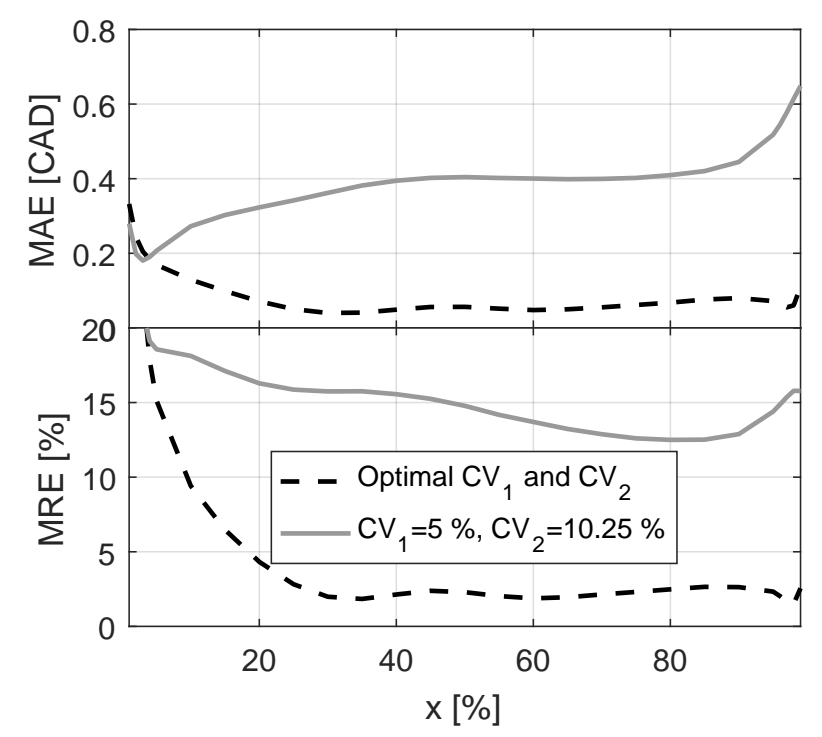

Figure 21. Mean absolute error (top) and mean relative error (bottom) for the variability propagation at each $\%$ of the evolution.

Note that $85 \%$ of the cycle-to-cycle variability observed can be explained by propagation of a constant exogenous noise with two normal probability distributions.

The model is able to represent the cycle-to-cycle variability during the combustion evolution (differences below $3 \%$ of MRE) if the noises are updated at each operating condition. The dependence of these two parameters $\left(C V_{1}\right.$ and $\left.C V_{2}\right)$ with the operating conditions is out of the scope in this paper because for a significant improvement in the final result, non-linear functions with at least 3 inputs (SA,n, $p_{\text {int }}$ ) need to be modelled.

One of the major drawbacks of the model is the prediction between the SOC and the CA5, where the error is above $20 \%$. This is mainly because of the assumption of the combustion starting at SA and no initial variability at this 
point.

\section{Results on transient dataset}

The signal provided by the intake pressure sensor has been used to phase all the information provided by the ECU, the prototyping system and the test cell. At each cycle the model has been analysed with the model inputs recorded and the in-cylinder pressure has been individually processed. Figure 22 shows a part of the test where the CA20 (top plot), CA50 (medium plot), and the CA90 (bottom plot) are shown. Here, cycle to cycle measurements are plotted with grey dots, and the model output has been represented with a black line.

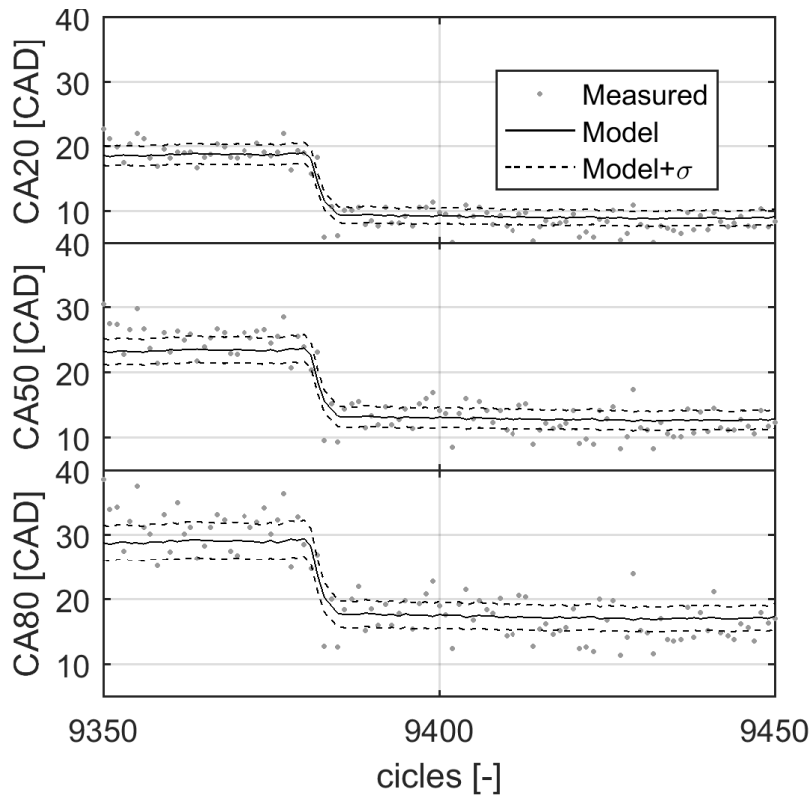

Figure 22. Cycle-to-cycle evolution and model output of the CA20 (top plot), CA50 (medium plot), and CA80 (bottom plot)

The model is capable of giving an adequate combustion phase evolution for each cycle while reproduces the increase of variability as the combustion approaches the EOC. For a quantitative analysis, the average $C A_{x}$ and its variation have been quantified with two IIR filters, through:

$$
\begin{aligned}
\overline{C A x}_{k+1} & =k_{f m} \overline{C A x}_{k}+\left(1-k_{f m}\right) C A x_{k+1} \\
\bar{\sigma}_{k+1}^{2} & =k_{f \sigma} \bar{\sigma}_{k}^{2}+\left(1-k_{f \sigma}\right) \sigma_{k+1}^{2}
\end{aligned}
$$

where $k_{f m}$ and $k_{f \sigma}$ are setted at 0.95 and 0.97 respectively, and are used to filter the CAx and the variability measured. The variance at each cycle $\left(\sigma^{2}\right)$ is obtained by:

$$
\sigma_{k}^{2}=\left(\overline{C A x}_{k}-C A x_{k}\right)^{2}
$$

Figure 23 shows the evolution of the CA50 and its variability during all the transient test. The experimental values are drawn with black line while the model results are represented by a thicker grey line.

The mean relative error of the model at each $\%$ is show in Figure 24. During this transient test the model has exhibit an average error on the combustion phasing of $5 \%$ at each $\%$ of

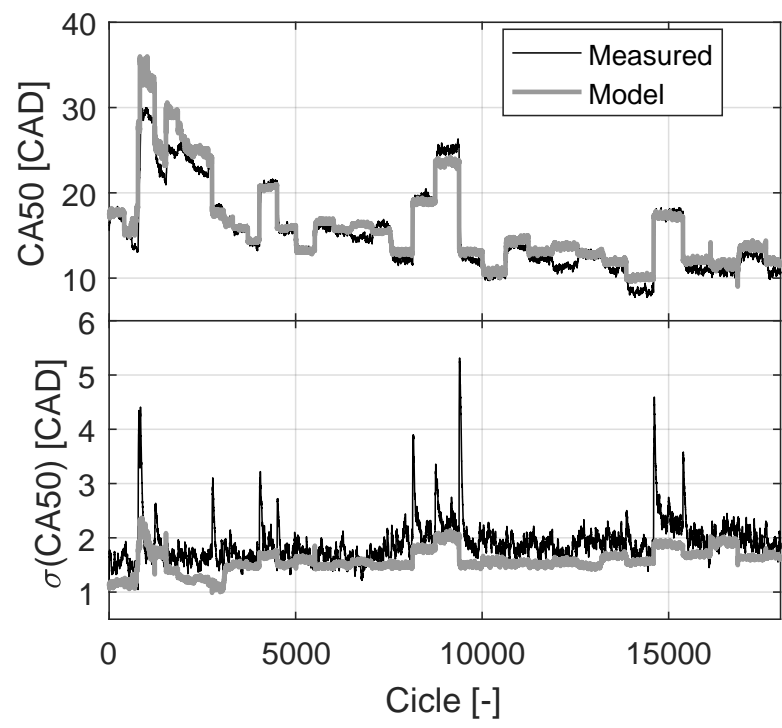

Figure 23. CA50 evolution and its variability during the transient test

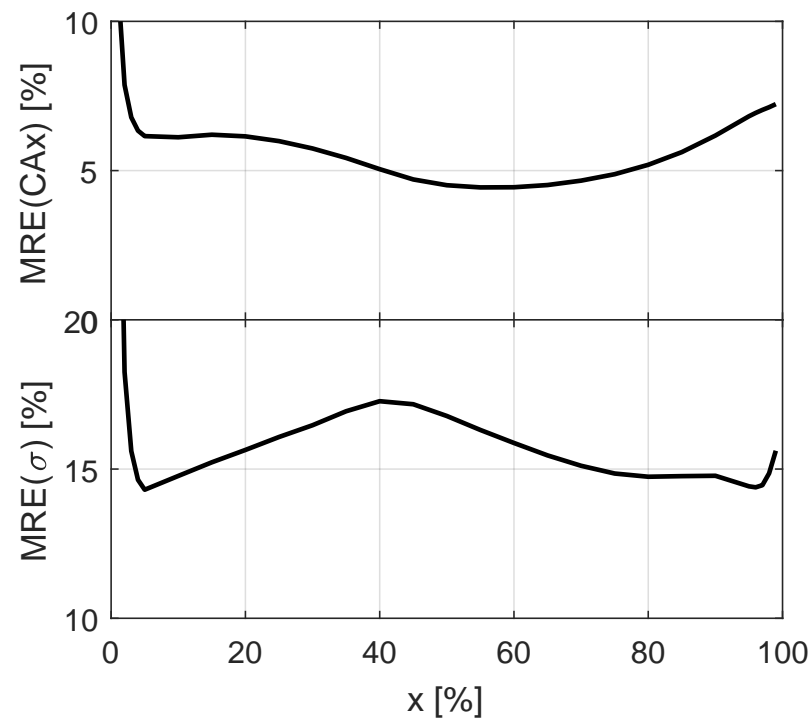

Figure 24. Mean relative error of the $\mathrm{CAx}$ and its variation predicted by the model

the combustion, while the error on the variability predicted grows up to the $15 \%$.

\section{Conclusions}

A combustion model for SI engines has been presented. The model is not only able to predict the average combustion phase evolution, but it also predicts the cycle-to-cycle variability at each $\%$ of the combustion.

The variability estimation is based on the propagation of two probability distributions (at the laminar flame speed and at the turbulent intensity) in a flame propagation model. A control oriented model is proposed by designing an algorithm that allows the propagation of the normal distribution by running just 5 times the model. Several 
corrections at some critical parameters have been also suggested to improve the precisions when varying the operating conditions.

The combustion model consists in 3 OL tables: two for the heat release calculation and a table to characterize the combustion model. The variability can be simulated with two constant probability distributions.

The model has been validated in an extensive test campaign with a state of the art four-stroke SI engine, where the engine speed, the SA, and the VGT were modified. The combustion model is able to precisely reproduce the average in-cylinder pressure and mass fraction burnt, while the propagation of the variabilities is able to predict the cycle-to-cycle variability with a mean relative errors of $15 \%$, nevertheless, because of the assumptions taken, the errors rapidly grow up before the CA5.

The model can be used to simulate the real behaviour of the engine in off-line applications or it can be programmed on-line to improve the performance of SA controllers.

\section{Acknowledgements}

The authors appreciate the technical support and the clues given by J. Israel Sánchez for the model development and also acknowledge the support of Spanish Ministerio de Economía, Industria y Competitividad through project TRA2016-78717-R.

\section{References}

1. Hao Wu. Study of spark ignition engine combustion model for the analysis of cyclic variation and combustion stability at lean operating conditions. 2015.

2. S. Wang, R. Prucka, Q. Zhu, M. Prucka, and H. Dourra. A real-time model for spark ignition engine combustion phasing prediction. SAE International Journal of Engines, 9(2), 2016.

3. N. Kim, I. Ko, and K. Min. Development of a zero-dimensional turbulence model for a spark ignition engine. International Journal of Engine Research, 20(4):441-451, 2019.

4. S. Keum, G. Zhu, Jr Grover, R., W. Zeng, C. Rutland, and T. . Kuo. A semi-empirical laminar-to-turbulent flame transition model coupled with $\mathrm{g}$ equation for early flame kernel development and combustion in spark-ignition engines. International Journal of Engine Research, 2019.

5. S. Wang, Q. Zhu, R. Prucka, M. Prucka, and H. Dourra. Input adaptation for control oriented physics-based si engine combustion models based on cylinder pressure feedback. SAE International Journal of Engines, 8(4), 2015.

6. X. Zhen, Y. Wang, S. Xu, Y. Zhu, C. Tao, T. Xu, and M. Song. The engine knock analysis - an overview. Applied Energy, 92:628-636, 2012.

7. P. Bares, D. Selmanaj, C. Guardiola, and C. Onder. Knock probability estimation through an in-cylinder temperature model with exogenous noise. Mechanical Systems and Signal Processing, 98:756-769, 2018.

8. R. C. Li and G. G. Zhu. A real-time pressure wave model for knock prediction and control. International Journal of Engine Research, 2019.
9. Y. Zhang, X. Shen, Y. Wu, and T. Shen. On-board knock probability map learning-based spark advance control for combustion engines. International Journal of Engine Research, 2019.

10. J. M. Spelina, J. C. Peyton Jones, and J. Frey. Stochastic simulation and analysis of a classical knock controller. International Journal of Engine Research, 16(3):461-473, 2015.

11. D. Neumann, C. Jörg, N. Peschke, J. Schaub, and T. Schnorbus. Real-time capable simulation of diesel combustion processes for hil applications. International Journal of Engine Research, 19(2):214-229, 2018.

12. E. Pipitone. A comparison between combustion phase indicators for optimal spark timing. Journal of Engineering for Gas Turbines and Power, 130(5), 2008.

13. P. Bares, D. Selmanaj, C. Guardiola, and C. Onder. A new knock event definition for knock detection and control optimization. Applied Thermal Engineering, 131:80-88, 2018.

14. J. C. Peyton Jones, J. M. Spelina, and J. Frey. Optimizing knock thresholds for improved knock control. International Journal of Engine Research, 15(1):123-132, 2014.

15. E. Pipitone. Spark ignition feedback control by means of combustion phase indicators on steady and transient operation. Journal of Dynamic Systems, Measurement and Control, Transactions of the ASME, 136(5), 2014.

16. Q. Zhu, R. Prucka, S. Wang, M. Prucka, and H. Dourra. Modelbased optimal combustion phasing control strategy for spark ignition engines. SAE International Journal of Engines, 9(2), 2016.

17. Q. Zhu, R. Prucka, S. Wang, M. Prucka, and H. Dourra. Control oriented modelling of engine imep variation. In ASME 2016 Internal Combustion Engine Fall Technical Conference, ICEF 2016, 2016.

18. Y. Zhang and T. Shen. On-board map learning-based combustion phase control in spark ignition engines. In 1st Annual IEEE Conference on Control Technology and Applications, CCTA 2017, volume 2017-January, pages 287292, 2017.

19. Y. Zhang and T. Shen. Cylinder pressure based combustion phase optimization and control in spark-ignited engines. Control Theory and Technology, 15(2):83-91, 2017.

20. Y. Zhang, J. Gao, and T. Shen. Combustion control of sparkignition engines based on map-learning. In Chinese Control Conference, CCC, volume 2018-July, pages 2950-2956, 2018.

21. Y. Zhang, X. Shen, and T. Shen. A survey on online learning and optimization for spark advance control of si engines. Science China Information Sciences, 61(7), 2018.

22. E. Corti, C. Forte, G. Mancini, and D. Moro. Automatic combustion phase calibration with extremum seeking approach. Journal of Engineering for Gas Turbines and Power, 136(9), 2014.

23. E. Corti, A. Cerofolini, N. Cavina, C. Forte, G. Mancini, D. Moro, F. Ponti, and V. Ravaglioli. Automatic calibration of control parameters based on merit function spectral analysis. In Energy Procedia, volume 45, pages 919-928, 2014.

24. D. Popović, M. Janković, S. Magner, and A. R. Teel. Extremum seeking methods for optimization of variable cam timing engine operation. IEEE Transactions on Control Systems Technology, 14(3):398-407, 2006.

25. E. Hellstrom, D. Lee, L. Jiang, A. G. Stefanopoulou, and H. Yilmaz. On-board calibration of spark timing by extremum 
seeking for flex-fuel engines. IEEE Transactions on Control Systems Technology, 21(6):2273-2279, 2013.

26. N. Ozdor, M. Dulger, and E. Sher. Cyclic variability in spark ignition engines a literature survey. SAE Technical Papers, 1994.

27. C. Pera, S. Chevillard, and J. Reveillon. Effects of residual burnt gas heterogeneity on early flame propagation and on cyclic variability in spark-ignited engines. Combustion and Flame, 160(6):1020-1032, 2013.

28. L. Zhao, A. A. Moiz, S. Som, N. Fogla, M. Bybee, S. Wahiduzzaman, M. Mirzaeian, F. Millo, and J. Kodavasal. Examining the role of flame topologies and in-cylinder flow fields on cyclic variability in spark-ignited engines using largeeddy simulation. International Journal of Engine Research, 19(8):886-904, 2018.

29. C. Pera, V. Knop, and J. Reveillon. Influence of flow and ignition fluctuations on cycle-to-cycle variations in early flame kernel growth. Proceedings of the Combustion Institute, 35(3):2897-2905, 2015.

30. P. Schiffmann, D. L. Reuss, and V. Sick. Empirical investigation of spark-ignited flame-initiation cycle-to-cycle variability in a homogeneous charge reciprocating engine. International Journal of Engine Research, 19(5):491-508, 2018.

31. B. Johansson. Cycle to cycle variations in s.i. engines-the effects of fluid flow and gas composition in the vicinity of the spark plug on early combustion. SAE Technical Papers, 1996.

32. E. Galloni. Analyses about parameters that affect cyclic variation in a spark ignition engine. Applied Thermal Engineering, 29(5-6):1131-1137, 2009.

33. S. Tamaki, Y. Sakayanagi, K. Sekiguchi, T. Ibuki, K. Tahara, and M. Sampei. On-line feedforward map generation for engine ignition timing control. In IFAC Proceedings Volumes (IFAC-PapersOnline), volume 19, pages 5691-5696, 2014.

34. Y. Zhang and T. Shen. Combustion variation feedback control approach for multi-cylinder spark ignition engines. IFACPapersOnLine, 51(31):105-110, 2018.

35. E. Corti and C. Forte. Spark advance real-time optimization based on combustion analysis. Journal of Engineering for Gas Turbines and Power, 133(9), 2011.

36. J. Gao, Y. Wu, and T. Shen. Experimental comparisons of hypothesis test and moving average based combustion phase controllers. ISA transactions, 65:504-515, 2016.

37. J. Gao, Y. Wu, and T. Shen. A statistical combustion phase control approach of si engines. Mechanical Systems and Signal Processing, 85:218-235, 2017.

38. D. Lee, L. Jiang, H. Yilmaz, and A. G. Stefanopoulou. Preliminary results on optimal variable valve timing and spark timing control via extremum seeking. In IFAC Proceedings Volumes (IFAC-PapersOnline), volume 43, pages 377-384, 2010.

39. A. Di Mauro, H. Chen, and V. Sick. Neural network prediction of cycle-to-cycle power variability in a spark-ignited internal combustion engine. Proceedings of the Combustion Institute, 37(4):4937-4944, 2019.

40. S. Urano, M. Nagai, and J. Kako. Study on the combustion control methodology for maximizing of engine thermal efficiency - the strategy for control of heat release pattern. In Chinese Control Conference, CCC, pages 9335-9340, 2017.

41. M. Lapuerta, O. Armas, and J. J. Hernández. Diagnosis of di diesel combustion from in-cylinder pressure signal by estimation of mean thermodynamic properties of the gas. Applied Thermal Engineering, 19(5):513-529, 1999.

42. M. A. Ceviz and I. Kaymaz. Temperature and air-fuel ratio dependent specific heat ratio functions for lean burned and unburned mixture. Energy Conversion and Management, 46(15-16):2387-2404, 2005.

43. J. A. Gatowski, E. N. Balles, K. M. Chun, F. E. Nelson, J. A. Ekchian, and J. B. Heywood. Heat release analysis of engine pressure data. SAE Technical Papers, 1984.

44. R. Egnell. Combustion diagnostics by means of multizone heat release analysis and no calculation. SAE Technical Papers, 1998.

45. G. Woschni. A universally applicable equation for the instantaneous heat transfer coefficient in the internal combustion engine. SAE Technical Papers, 1967.

46. N. C. Blizard and J. C. Keck. Experimental and theoretical investigation of turbulent burning model for internal combustion engines. SAE Technical Papers, 1974.

47. S. G. Poulos and J. B. Heywood. The effect of chamber geometry on spark-ignition engine combustion. SAE Technical Papers, 1983.

48. C. Guardiola, V. Triantopoulos, P. Bares, S. Bohac, and A. Stefanopoulou. Simultaneous estimation of intake and residual mass using in-cylinder pressure in an engine with negative valve overlap. IFAC-PapersOnLine, 49(11):461-468, 2016.

49. S. Wang, R. Prucka, M. Prucka, and H. Dourra. Controloriented residual gas mass prediction for spark ignition engines. International Journal of Engine Research, 16(7):897907, 2015.

50. J.B. Heywood. Internal Combustion Engine Fundamentals. McGraw-Hill, Inc., 1988.

51. R. J. Tabaczynski, C. R. Ferguson, and K. Radhakrishnan. A turbulent entrainment model for spark-ignition engine combustion. SAE Technical Papers, 1977.

52. J. C. Keck. Turbulent flame structure and speed in sparkignition engines. Symposium (International) on Combustion, 19(1):1451-1466, 1982.

53. V. W. Wong and D. P. Hoult. Rapid distortion theory applied to turbulent combustion. SAE Technical Papers, 1979. 